
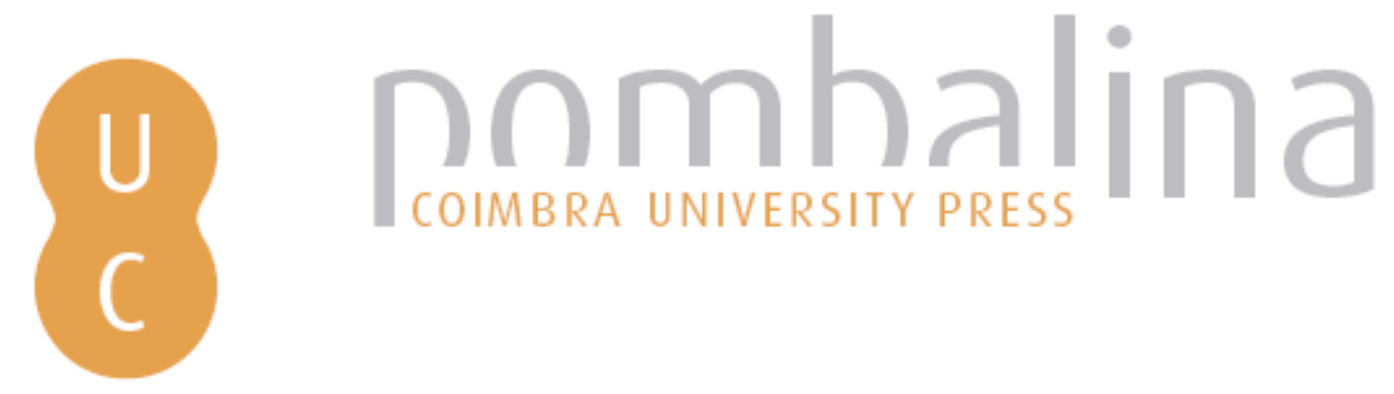

\title{
Turismo e cinema: uma outra abordagem através do filme de animação Astérix - 0 Domínio dos Deuses
}

Autor(es): $\quad$ Marques, Jorge Humberto Soares

Publicado por: Imprensa da Universidade de Coimbra

URL

persistente: URI:http://hdl.handle.net/10316.2/43530

DOI: $\quad$ DOI:https://doi.org/10.14195/978-989-26-1343-7_34

Accessed : $\quad$ 26-Apr-2023 13:33:15

A navegação consulta e descarregamento dos títulos inseridos nas Bibliotecas Digitais UC Digitalis, UC Pombalina e UC Impactum, pressupõem a aceitação plena e sem reservas dos Termos e Condições de Uso destas Bibliotecas Digitais, disponíveis em https://digitalis.uc.pt/pt-pt/termos.

Conforme exposto nos referidos Termos e Condições de Uso, o descarregamento de títulos de acesso restrito requer uma licença válida de autorização devendo o utilizador aceder ao(s) documento(s) a partir de um endereço de IP da instituição detentora da supramencionada licença.

Ao utilizador é apenas permitido o descarregamento para uso pessoal, pelo que o emprego do(s) título(s) descarregado(s) para outro fim, designadamente comercial, carece de autorização do respetivo autor ou editor da obra.

Na medida em que todas as obras da UC Digitalis se encontram protegidas pelo Código do Direito de Autor e Direitos Conexos e demais legislação aplicável, toda a cópia, parcial ou total, deste documento, nos casos em que é legalmente admitida, deverá conter ou fazer-se acompanhar por este aviso.

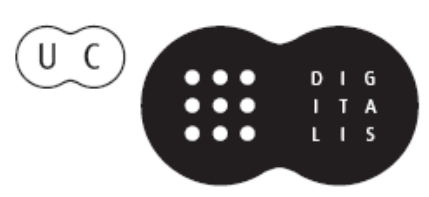




\section{FERNANDA CRAVIDÃO}

\section{IÚCIO CUNHA}

PAULA SANTANA

\section{NORBERTOSANTOS}

(ORG.)

\section{ESPAÇOS E TEMPOS EM GEOGRAFIA}

HOMENAGEM A ANTÓNIO GAMA

IMPRENISA DÁ UNIVERSIDADE DE COIMBRA COIMBRA UNIVERSITY PRESS

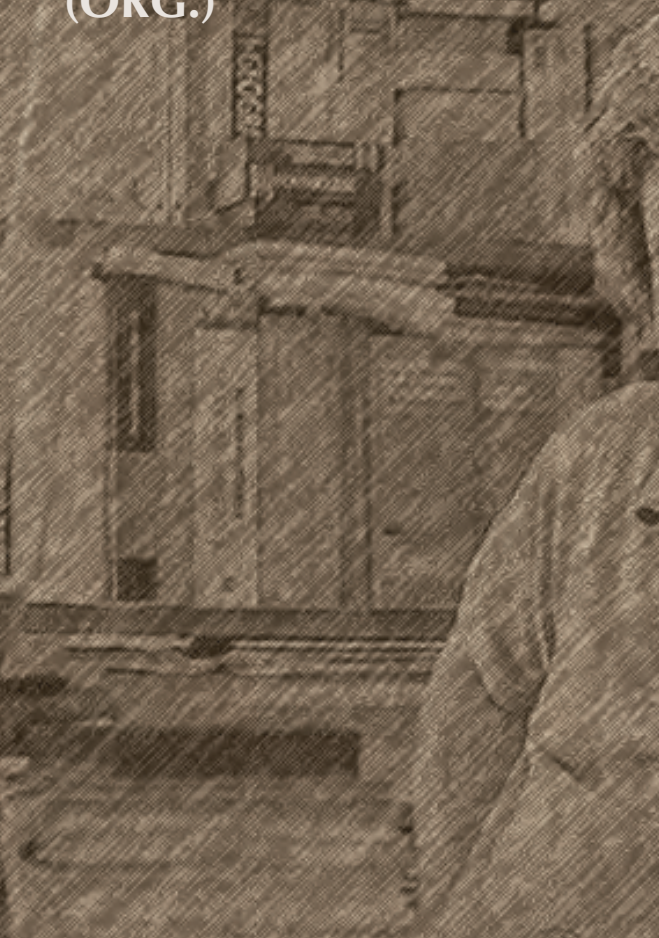




\title{
TURISMO E CINEMA: UMA OUTRA ABORDAGEM ATRAVÉS DO FILME DE ANIMAÇÃO ASTÉRIX - O DOMÍNIO DOS DEUSES
}

\author{
Jorge Humberto Soares Marques/jorgehsm@sapo.pt \\ Universidade Portucalense, Porto \\ e Centro de Estudos em Geografia \\ e Ordenamento do Território, Coimbra
}

\section{Introduçáo}

O cinema tem a magia de nos transportar para o mundo do sonho, da aventura, do romântico, do entretenimento. Permite-nos apreender novos conhecimentos, refletir sobre os temas mais diversos e conhecer novos lugares, onde o conteúdo e a forma das narrativas proporcionam a construção de imagens mentais. Este constructo, associado à vontade de viajar e de conhecer os lugares, origina aquilo a que hoje em dia chamamos de Turismo Cinematográfico. Desta forma, constrói-se uma relação muito direta entre cinema e território que pode ser analisada sob duas perspetivas (Orueta e Valdés, 2007; Almeida et al, 2009). Uma delas refere-se à influência que os elementos geográficos e as características territoriais têm na realização e produção cinematográfica (o território enquanto cenário), a outra tem a ver com a influência que o cinema tem no território e na sua perceção (o território enquanto espaço de visitação), com o cinema a desempenhar um papel importante no marketing territorial e na projeçâo turística dos territórios. 
Esta relação entre cinema e marketing territorial tem sido desenvolvida ao longo dos últimos anos. Por um lado, através da atuação das entidades gestoras dos destinos (Destination Management Organizations ou DMO's), que exploram a relação entre as narrativas e os territórios dos êxitos de bilheteira através de tours e ofertas turísticas específicas, como por exemplo no caso das séries de filmes de Harry Potter (Londres) e O Senhor dos Anéis (Nova Zelândia). Por outro, através da atuação das entidades públicas e institucionais para captarem o interesse de estúdios e realizadores famosos para rodarem filmes nos seus países, como é o caso de Woody Allen e as cidades que nos últimos anos tem escolhido: Match Point (Londres), Vicky Cristina Barcelona (Barcelona), Meia-Noite em Paris (Paris), Para Roma com Amor (Roma) ou Magia ao Luar (Nice), entre outros. A cidade de Lisboa também tem surgido por algumas vezes associada ao nome do cineasta e não será de estranhar que no futuro surja esta possibilidade de projeção da imagem turística através do cinema de Hollywood. Algo que de resto já acontece com a indústria cinematográfica indiana (Bollywood), que nos últimos anos tem optado por Portugal para realizar alguns dos seus filmes, como por exemplo Balupu (2013), Bachchan (2014), Pandaga Chesko (2015) e Chakravyuha (2016). O mais recente investimento consiste no filme AirportShaira \& $M e$, rodado em Lisboa, Sintra, Porto, Beja e praias do Algarve, com estreia prevista para 2017. O facto de estarmos em presença da maior indústria mundial de cinema em termos de bilheteira e uma das maiores em número de filmes produzidos anualmente mostra bem a importância que o cinema poderá ter para o turismo e para a projeção dos territórios.

A ligação entre turismo e cinema pode assumir diferentes formas, incluindo a produção de documentários para a divulgação de destinos turísticos, a criação de produtos turísticos a partir dos estúdios de cinema, o turismo de negócios associado aos festivais de cinema e, por último, a deslocação a um lugar por aí ter sido rodado um determinado filme (Almeida et al, 2009). Tratando-se de um tema relativamente recente, nos últimos anos têm surgido alguns estudos sobre este fenómeno que associa o cinema e o turismo (Duque, 2013). Bèric et al (2013) resumem as cinco temáticas predominantes identificadas nos estudos sobre o Turismo Cinematográfico: i) a influência que o filme tem na decisão 
de viajar; ii) as características e motivaçóes dos turistas cinematográficos; iii) as características e motivaçóes dos turistas "televisivos" (screen tourists); iv) os impactes do turismo cinematográfico no volume de visitas e nos residentes; e 5) as atividades de marketing territorial relacionadas com o turismo cinematográfico.

Com este texto pretende-se explorar uma perspetiva alternativa sobre a relação entre turismo e cinema: a perspetiva educacional. A forma como um filme (neste caso de animação) expóe de uma forma direta alguns pontos de reflexão pertinentes nos domínios do lazer e do turismo. Este tipo de películas poderá ser utilizado como ferramenta de apoio em contexto de aula para o desenvolvimento da reflexão crítica nos alunos, possibilitando a identificação e o debate de fenómenos turísticos que se encontrem mais ou menos explícitos nas narrativas. Neste caso concreto, podemos ver retratada a importância que o lazer tem na vida das pessoas e assistir ao processo de "turistificação" do território e os respetivos impactes, temas que iremos abordar de seguida.

\section{O projeto turístico de César: liçôes sobre o lazer}

O filme aqui analisado tem o título Astérix: O Domínio dos Deuses (da versão original Astérix: Le Domaine des Dieux). Foi realizado por Louis Clichy e Alexandre Astier e estreou em Portugal em 2014. É baseado no álbum de banda desenhada de Albert Uderzo e René Goscinny, publicado em França em 1971 (17. a obra assinada por esta dupla). A estória passa-se na Gália, no ano 50 antes de Cristo, e retrata mais uma tentativa de Júlio César e do seu exército para conquistar a aldeia dos gauleses. Desta vez, após as inúmeras tentativas falhadas através da força, Júlio César traça um plano diferente que consiste em construir um condomínio de luxo mesmo ao lado da aldeia dos gauleses. O objetivo é que, através do enaltecimento das práticas de lazer e do culto do ócio, os gauleses se mudem para o condomínio, deixando a aldeia à mercê de Júlio César.

O filme começa com a apresentação do plano turístico que Júlio César idealizou e que designou de Domínio dos Deuses. Para além do alojamento, o 
projeto inclui a construção de uma arena de gladiadores que seria o elemento fulcral da oferta turística associada a este lugar. As ideias base deste projeto remetem-nos, desde logo, para os princípios em que assentam os resorts turísticos dos tempos de hoje. Tal como no Domínio dos Deuses, nos resorts encontramos uma oferta integrada de alojamento, serviços de suporte e atividades de recreio e lazer que proporciona uma experiência turística muito concentrada, quer no tempo, quer no espaço e, por isso, massificada. $\mathrm{O}$ turismo massificado, por sua vez, significa geralmente maiores impactes ambientais, económicos e socioculturais, aos quais teremos oportunidade de voltar neste texto.

No início da narrativa, os escravos ao serviço do império romano têm a tarefa de desflorestar uma grande área junto à aldeia para aí se poder construir o complexo. Para evitar que este plano avance, Astérix e Obélix tentam libertar os escravos, dando-lhes a beber da poção mágica que torna os gauleses invencíveis. No entanto, os escravos veem aqui uma oportunidade que vai muito para além da sua libertação imediata. Através da força, reivindicam salário, direito a férias, três refeiçóes por dia e quando o condomínio tiver sido por eles concluído querem ser libertados e ter direito a um apartamento. A partir deste contexto, podemos inferir sobre as transformaçóes ocorridas ao longo dos séculos que contribuíram para a construção de sucessivas análises à problemática do tempo livre e do lazer. Como exemplos, podemos apontar as progressivas reduçóes do tempo de trabalho e consequente aumento do tempo livre, a conquista do direito a férias pagas, o aumento da esperança média de vida, a antecipação da idade de reforma, o desenvolvimento dos meios de transporte e das comunicaçóes, o aumento da inserçáo da mulher no mercado de trabalho e o desenvolvimento do consumo massificado (refletido também no aumento do consumo das práticas de lazer). Ao longo dos tempos, a redução do tempo de trabalho e o reconhecimento do direito ao lazer pelas classes trabalhadoras levou a que Joffre Dumazedier (1962) desenvolvesse o conceito de "civilização dos lazeres", assente na ideia de generalizaçáo do acesso ao lazer por todas as classes sociais. De acordo com este autor, são três as funçôes que se interrelacionam no conceito de lazer (os 3 D's de Dumazedier): i) o descanso (libertação da fadiga); ii) o divertimento (através da recreação, do entretenimento, como 
forma de atingir o equilíbrio da vida no quotidiano, compensando o esforço que despendemos no trabalho); iii) o desenvolvimento (através da participação social mais livre). O lazer consiste entáo no conjunto de ocupaçóes às quais o indivíduo se dedica de um modo voluntário, seja para descansar, seja para se divertir, seja para desenvolver a sua formação desinteressada, a sua participação social voluntária, liberto das suas obrigaçôes profissionais, familiares e sociais, envolto de carácter libertador, gratuito (sem obrigação), hedonístico e pessoal (Dumazedier, 1962). Estas são então quatro as características principais do lazer: i) carácter livre - resulta de uma livre escolha, liberta das obrigaçóes impostas pela sociedade; ii) carácter desinteressado - na medida em que o lazer não está necessariamente submetido ao lucro, nem a obrigaçôes domésticas, nem a qualquer outro princípio ideológico [políticos ou espirituais, por exemplo]; iii) carácter hedonístico - encarado através de uma perspetiva positiva no que diz respeito às necessidades individuais; iv) carácter pessoal - lazer como forma para satisfazer as necessidades do indivíduo, como libertação pessoal das obrigaçôes impostas pela sociedade.

Com o desenrolar da estória, é então possível identificar duas situaçóes distintas relacionadas com as práticas de lazer que poderão sustentar diferentes reflexôes. A primeira diz respeito à evolução da generalização do acesso às práticas de lazer e à sua gradual valorizaçáo enquanto elemento fulcral nas sociedades; a segunda diz respeito às diferentes formas e lugares que as práticas de lazer podem assumir. Desde logo são identificados dois territórios distintos onde os romanos podem desenvolver as suas atividades de lazer. O primeiro é o território urbano, onde é dado destaque às arenas e aos espetáculos de gladiadores. O segundo é o território não urbano, de natureza ou, se quisermos, rural, que consiste na floresta onde se localiza a aldeia gaulesa e onde será implementado o complexo turístico. Mais à frente na estória, já com o complexo construído e habitado, podemos ver os visitantes a participar em diversas práticas de lazer, nomeadamente spas, peças de teatro, aulas de fitness e visitas guiadas. Em última análise, podemos ainda encarar aqui o turismo enquanto prática de lazer organizada, de maior complexidade, que envolve deslocaçáo e estadia fora do ambiente habitual de residência e de trabalho, em contraposição com outras 
atividades de lazer mais imediatas e com menos grau de complexidade na sua organização, como é o caso de assistir a um espetáculo de gladiadores.

\section{A promoção turística: alguns aspetos sobre posicionamento e imagem}

Com a idealização do projeto turístico surgiu a necessidade de o promover junto do povo romano que, no início, estava pouco interessado em passar férias num espaço de lazer perto da aldeia dos gauleses. Como estratégia de promoção turística, César decidiu sortear umas férias com "tudo incluído" no Domínio dos Deuses durante o intervalo de um espetáculo de gladiadores, captando deste modo a atenção dos romanos. A mensagem do anúncio apelou aos romanos e romanas fartos da atmosfera poluída, do barulho, do frenesim e do "trânsito" da cidade de Roma, propondo como alternativa uma estada num apartamento do Domínio dos Deuses, localizado em ambiente tranquilo e num cenário verde, onde se podia usufruir de diversas atividades de lazer e de animaçáo. Esta cena evoca de forma notória a importância de promover e projetar os destinos turísticos junto dos públicos-alvo e de trabalhar o posicionamento e a imagem do destino. O posicionamento consiste na abordagem de comunicaçáo que tem como objetivo assegurar uma posiçáo de valor junto dos mercados-alvo. O posicionamento não é o que se faz ao produto, mas sim o que se faz à mente dos consumidores (Ries e Trout, 1986). Ou seja, consiste na forma como o produto e os seus atributos principais são definidos pelos consumidores, referindo-se ao lugar que o produto ocupa na mente dos consumidores (Kotler e Armstrong, 2004), criando desta forma uma imagem mental do destino. Como refere Gartrel (1994), a decisão final na escolha de um destino turístico, por parte do visitante, é baseada no conjunto de benefícios que este espera obter através do consumo/experiência turística, o mesmo será dizer que são criadas expectativas no potencial consumidor, resultantes da formaçáo de uma imagem prévia. Neste contexto, as açôes de marketing e promoção desempenham um papel fundamental na promoção dos destinos turísticos porque despertam a atenção para os destinos como potenciais locais a visitar, criando 
imagens positivas do destino e motivando os turistas para viajarem para esse destino (Di Marino, 2008). Esta parte da narrativa cinematográfica mostrou isso mesmo: a construçáo de expectativas, de desejos e de imagens na mente dos romanos através da ação direta do marketing. E terão sido essas expectativas e imagens mentais que levaram os romanos a superar o medo dos gauleses e a irem para um complexo turístico mesmo ao lado a aldeia. Isto reflete também a importância do estudo das motivaçóes e dos perfis psicológicos dos indivíduos para o desenvolvimento de estratégias de marketing adequadas aos diferentes segmentos de mercado ou públicos-alvo.

\section{O início da construçáo: aspetos sobre os impactes ambientais}

Após o início da construção do complexo, a narrativa explora os principais impactes ambientais provocados na floresta onde se localiza a aldeia gaulesa, mais concretamente através da desflorestação e destruição do habitat natural que levou ao desaparecimento dos javalis, que eram um dos principais alimentos da dieta de Obélix. A escassez de alimento traduziu-se depois na falta de força do gaulês e na sua incapacidade para ajudar a proteger a sua aldeia.

Esta questão da desflorestação remete-nos para a problemática associada aos efeitos negativos que o desenvolvimento do turismo poderá provocar no meio ambiente, principalmente quando se trata de um desenvolvimento veloz, em grande escala e sem os devidos cuidados de planeamento. Contudo, o desenvolvimento turístico poderá significar também o lado oposto, ou seja, a proteção e preservação da natureza. Tal como refere Eusébio (2006), em termos ambientais o turismo pode contribuir para a degradação de um determinado destino ou para a sua conservação. O primeiro tipo de efeitos é por excelência aquele que tem sido objeto de uma maior reflexão devido às implicaçóes que poderá desempenhar na sobrevivência dos destinos turísticos. Quando o turismo é responsável por elevados índices de poluição das águas, de poluição do ar, de poluição sonora, de poluição visual e de destruição da flora e da fauna dos destinos turísticos estamos a assistir a uma destruição dos seus recursos 
básicos. No entanto, tem-se verificado uma crescente consciencialização em torno dos impactes que algumas formas de desenvolvimento turístico têm no ambiente. Alguns fatores como as chuvas ácidas, o buraco na camada de ozono e o aquecimento global têm originado uma maior sensibilização por parte dos governos, dos turistas e dos stakeholders dos destinos turísticos relativamente às questóes ambientais (Lickorish e Jenkins, 1997), promovendo cada vez mais o desenvolvimento das atividades e práticas turísticas num contexto "amigo do ambiente", falando-se cada vez mais em turismo sustentável, turismo ambiental e ecoturismo. Importa, contudo, salientar que não é fácil a identificação dos reais impactes ambientais do turismo, sobretudo quando se trata de distinguir os impactes oriundos especificamente da atividade turística daqueles que resultam de outras atividades económicas. Apesar destas dificuldades, os principais impactes ambientais negativos e positivos geralmente associados ao turismo, dependem diretamente da forma como o desenvolvimento turístico é planeado e controlado, das próprias características dos destinos e da escala que a atividade turística representa (Lickorish e Jenkins, 1997). É um facto que, quanto mais elevado for o grau de massificação do turismo, mais elevada é a propensão para causar impactes ambientais negativos.

\section{A chegada dos turistas e os impactes culturais e socioeconómicos}

Com a construção do complexo turístico, e antes que Astérix e Obélix tivessem tempo para o evitar, chegaram em grande número os turistas romanos. $\mathrm{O}$ uso intensivo deste novo espaço criado propositadamente para fins turísticos começava a verificar-se. Os gauleses decidiram então seguir outras estratégias para afugentar os turistas romanos e destruírem os edifícios. Fizeram chover com a sua poção mágica, colocaram peixe podre junto dos alojamentos para criar mau cheiro e fizeram barulho à noite na tentativa de fazer com que os romanos se decidissem a regressar a Roma. Contudo, aquilo que se verificou foi o oposto. Mesmo com estas condiçôes desfavoráveis, os turistas romanos continuavam a preferir este lugar na Gália, por ser diferente, pelo escape 
à rotina, pela fuga à pressão urbana e pela experiência do contacto com a população local. Foi este contacto com os locais que fez com que os gauleses começassem a identificar vantagens da presença dos romanos, principalmente ao nível económico, pois iam à sua aldeia comprar peixe e outros bens alimentícios, bem como souvenirs e artefactos locais que pudessem mostrar um pouco a identidade e tipicidade locais. A partir daqui começaram a surgir conflitos entre os habitantes da aldeia, principalmente devido à concorrência e guerra pelos sestércios dos romanos. Surgiu a especulação dos preços, ajudada pelo facto de os romanos encararem a inflação como elemento valorizador daquilo que estavam a comprar, e a adulteração das características dos artefactos e objetos, consequência de uma produção em escala e estandardizada. Foram introduzidas também novas formas de promoçáo e de campanhas promocionais através de neons, cartazes luminosos e "novas roupagens" nas bancas de comércio local de modo a captar a atenção dos turistas e a aumentar as receitas turísticas. Isto levou a uma alteração profunda na vida quotidiana da aldeia, com o aparecimento de novos negócios turísticos, como visitas guiadas e produção e venda de souvenirs. As características socioculturais da aldeia foram assim adulteradas pelo processo de "turistificação", levando a uma perda de identidade e culminando com a vontade de quase toda a comunidade em se mudar para o condomínio turístico, atraída pela sedução das ofertas e práticas de lazer. Desta forma, verificou-se a adulteraçáo dos modos de vida com a terciarização da sociedade, tal como defende Santos (2001) ao referir que a valorização do lazer veio desencadear alteraçôes nos hábitos de consumo, nas relaçôes sociais e nas funçôes do espaço, sendo que estas mudanças acentuam a emergência teórica de tratar os temas do consumo, do lazer e da terciarizaçáo como processos sociais que se moldam continuadamente de forma recíproca (Santos, 2001).

A temática do turismo massificado está muito presente na narrativa, bem como os principais impactes económicos e socioculturais de uma construçáo turística massiva e da afluência de grandes fluxos de visitantes. Efetivamente, o turismo é umas das atividades que mais contribui para o desenvolvimento económico, sociocultural e ambiental dos destinos. Durante muito tempo, os 
impactes económicos positivos que o turismo representa para os destinos levou a que outros fatores sociais, culturais e ambientais fossem descurados, principalmente porque os impactes económicos são muito mais fáceis de identificar e medir que os restantes, pelo menos no que diz respeito a curto e médio prazo. No entanto, essa tendência foi-se alterando ao longo dos tempos originando uma crescente consciencialização da necessidade de se considerarem as questóes ambientais e as comunidades locais juntamente com os aspetos económicos no planeamento do desenvolvimento turístico dos destinos (Boniface e Cooper, 2009), tal como é evidenciado na Declaração de Manila proposta pela OMT e adotada em 1980, na qual é reforçada a importância da preservação dos recursos naturais e culturais para o desenvolvimento turístico dos destinos e também o bem-estar das populaçôes locais (Lickorish e Jenkins, 1997). De facto, se não houver planeamento e desenvolvimento estruturados numa base de sustentabilidade, esta atividade, especialmente quando massificada, pode trazer sérios impactes negativos a vários níveis. É um facto evidente que quando se fala em impactes económicos do turismo, a tendência é associá-los aos impactes positivos que representa nas populaçóes locais e nas regióes de destino, através da criação de empresas, de emprego e de aumento dos rendimentos, entre outros, enquanto os aspetos ambientais e socioculturais geralmente são associados aos impactes negativos que a atividade turística acarreta, como a destruição de habitats naturais, poluiçãoo, perda de identidade das populaçôes locais, entre outros. Todavia, como referem Cooper et al. (2005) e Goeldner e Ritchie (2006), os impactes do turismo geralmente englobam uma mistura de características positivas e negativas e afetam tanto os visitantes quanto as populações locais.

Os benefícios económicos dizem respeito principalmente à criação de novos postos de trabalho, à contribuição para o saldo da balança de pagamentos, à criação de rendimentos, ao aumento das receitas do Estado através do pagamento de impostos, à melhoria da estrutura económica do destino através do efeito multiplicador que origina, à diversificação da estrutura produtiva no destino e à contribuição para o aumento das exportaçóes. Importa ainda diferenciar os benefícios diretos (ou efeitos primários) e os benefícios indiretos e induzidos 
(efeitos secundários) da atividade económica gerada pelo turismo. De acordo com Eusébio (2006), os benefícios diretos resultam diretamente das despesas realizadas pelos visitantes no consumo de bens e serviços nos destinos. Estas despesas contribuem, assim, para o aumento das receitas das indústrias que vendem bens e serviços aos visitantes, dos rendimentos dos trabalhadores que exercem uma atividade remunerada nas indústrias que vendem bens e serviços aos visitantes, dos rendimentos dos proprietários das indústrias que vendem bens e serviços aos visitantes através da distribuição de dividendos, dos rendimentos dos proprietários de equipamentos através do pagamento de rendas, dos rendimentos do setor financeiro através da remuneraçáo do fator capital, para o aumento dos níveis de emprego, tanto no setor público como privado, e para o aumento dos impostos pagos ao Estado como consequência do consumo de bens e serviços locais por parte dos visitantes.

No que diz respeito aos custos ou prejuízos económicos do turismo, os principais referem-se à sazonalidade da produçáo (e consumo) com impactes evidentes na criação de empregos sazonais, ao aumento da importaçáo de bens e serviços de modo a satisfazer as necessidades dos visitantes, à excessiva dependência do turismo como principal atividade económica, ao aumento das despesas públicas associadas (aumento dos serviços relacionados com segurança, saúde e manutenção de infraestruturas, entre outros), ao aumento da inflação e ao aumento da pressão sobre a taxa de câmbio (o aumento das despesas turísticas numa determinada regiáo origina o aumento da procura de moeda nacional, originando uma revalorizaçáo da moeda e, nesta medida, podendo contribuir para uma diminuição das exportaçôes).

No filme é possível identificar claramente aspetos económicos positivos provenientes do turismo, como a criação de rendimentos e de empregos. Por outro lado, também mostra o processo de aumento da inflaçáo, muito associado a destinos muito procurados. Ao constatarem que os produtos que vendiam eram mais baratos que em Roma, os gauleses rapidamente aumentaram os preços para valores muito acima do preço e qualidade iniciais.

Já os impactes socioculturais do turismo referem-se às mudanças que a afluência de visitantes provoca nas comunidades locais, no seu estilo de vida, na 
sua cultura. Como referem Mathieson e Wall (1982), os impactes socioculturais resultam essencialmente do contacto que é estabelecido entre o visitante e a comunidade anfitriá, podendo ocorrer em maior ou menor escala, dependendo do tipo de turismo praticado, das características socioculturais dos turistas, do desenvolvimento das regióes e da atitude dos residentes face aos visitantes. A este respeito Valene Smith (1989) refere que a atividade turística nem sempre é negativa ou prejudicial para as culturas e povos locais, pois muitas vezes os turistas procuram oportunidades para conhecer e aprender mais sobres as comunidades locais e as suas culturas, surgindo muitas vezes o turismo como uma ponte para uma melhor apreciação e compreensão da diversidade cultural que há no mundo (Smith, 1989). Desta forma, o turismo poderá ser visto como um importante meio para promover as relações culturais e a cooperação entre os povos. Todavia, essa interação poderá trazer várias consequências para a vida dos residentes, como por exemplo tensóes culturais, sociais e morais, especialmente quando são grandes as diferenças socioculturais entre os visitantes e as populaçóes locais.

No filme, a pressão turística sobre a cultura da aldeia levou a modificaçóes profundas sobre os modos de vida e a própria cultura local, originando a adulteração das características dos produtos vendidos e apostando em economias de escala que desproviam os objetos da sua autenticidade e valor cultural. À escala global, são vários os efeitos socioculturais negativos que podem ser identificados com a chegada de elevados fluxos turísticos, nomeadamente ao nível de: i) alteraçóes das atividades tradicionais, como consequência do facto de os habitantes locais optarem por outras atividades ligadas diretamente ao turismo; ii) mercantilização da cultura através de uma excessiva encenação dos eventos culturais para satisfazer os turistas, comprometendo desta forma a autenticidade e o significado cultural local; iii) propagação de doenças infetocontagiosas, como é o caso do vírus HIV, entre outras; iv) padronização da oferta turística, refletindo a perda da diversidade cultural, dos princípios e crenças locais; v) conflitos entre visitantes e população local relacionados com dificuldades de acesso às atividades de lazer originadas pelo aumento dos fluxos turísticos [ex.: filas de espera muito demoradas para acesso às atraçóes turísticas, 
congestionamento de pessoas em monumentos, museus, etc.]; vi) aumento do tráfego urbano, originando [ou aumentando] problemas de estacionamento e engarrafamentos nas estradas; vii) destruição e descaracterização do património histórico e cultural; viii) aumento da criminalidade, da prostituição e do jogo, associados a um acréscimo de pessoas oriundas de outra região ou país (Cooper et al., 2005; Mathieson e Wall, 1982). Tudo isto leva a que, em muitos casos, a populaçáo local ganhe uma certa hostilidade em relaçáo aos visitantes e, como tal, o conceito de hospitalidade, muito presente nas questóes do turismo, fique definitivamente comprometido.

Apesar dos efeitos socioculturais negativos que o desenvolvimento do turismo causa nas regióes de destino, existem outros que, pelo contrário, trazem benefícios para as comunidades locais. Aqueles que são mais frequentemente identificados na bibliografia consistem nos seguintes: i) melhoria nas infraestruturas básicas que oferecem condições necessárias para o bem-estar do visitante e, consequentemente, da comunidade anfitriã, permitindo a todos o acesso, por exemplo, a serviços de transporte, comunicação, energia elétrica e saneamento básico, entre outros; ii) melhoria dos serviços de saúde e respetivas infraestruturas; iii) aumento do interesse da comunidade local pela sua própria cultura, tradiçóes, costumes e património histórico, contribuindo para o aumento do interesse da comunidade local para a preservação dos seus monumentos, locais históricos, manifestaçóes culturais, gastronomia e arte; iv) rejuvenescimento das artes, ofícios, produtos e tradiçóes locais; v) desenvolvimento de novas oportunidades de lazer e entretenimento que beneficiam tanto o visitante quanto o residente; vi) recuperação e valorização turística do património arquitetónico que acaba por beneficiar também a população local.

Os principais benefícios socioculturais que podemos identificar no filme, ainda que de forma subjacente, são o aumento do interesse da comunidade local pela sua própria cultura e o rejuvenescimento das artes, ofícios, produtos e tradiçóes locais. 


\section{Consideraçóes finais}

A parte final do filme Astérix: o Dominio dos Deuses retrata aquilo a que as estórias do herói gaulês sempre nos habituaram. Astérix e os seus amigos conseguem derrotar o imperador César e terminar com os seus planos para destruir a aldeia. Após a turbulência causada por uma invasão de turistas romanos, os gauleses conseguem finalmente "convencê-los" a abandonar o complexo turístico, restabelecendo a ordem e sossego da aldeia.

Ao longo da estória, foi possível assistir a alguns dos principais fenómenos turísticos, como a relação entre tempo livre e lazer, a massificaçáo turística e os impactes do turismo. Além disso, foi possível constatar também o desenrolar das diversas etapas num processo de desenvolvimento de um território como área-destino, podendo comparar-se este processo ao Ciclo de Vida de um Destino Turístico (TALC - Tourist Area Life Cycle), de Richard Butler (1980), que sugere que a evoluçáo dos destinos turísticos deverá ocorrer em seis fases principais: i) exploração; ii) envolvimento; iii) desenvolvimento; iv) consolidaçấo; v) estagnaçáo e vi) declínio ou rejuvenescimento. No caso do Domínio dos Deuses, o ciclo de vida do destino terminou em declínio e, mais concretamente, na sua extinção enquanto destino turístico. As temáticas retratadas no filme chamam a atenção principalmente para os perigos da falta de planeamento e de desenvolvimento integrado do turismo, que poderá acontecer se as entidades responsáveis pela gestáo dos destinos olharem apenas para os objetivos finais e descurarem todo o processo de contextualização e adequação das políticas e estratégias de desenvolvimento às características territoriais. Em todo este processo, é fundamental a integração da população local e da sua identidade cultural.

A análise e reflexão descritas neste texto, ainda que de forma não exaustiva, pretendem mostrar como certos tipos de filmes poderão contribuir para o desenvolvimento do estudo do fenómeno do turismo, estimulando a reflexão e o debate sobre os fenómenos turísticos retratados nas películas. Esta forma de desenvolvimento de conhecimentos teóricos sobre as temáticas do turismo poderá revelar-se útil principalmente em contexto de aula, enquanto espaço de eleição para a partilha e debate de ideias. Mas também deverá contribuir para 
ajudar a trilhar um caminho ainda pouco explorado relacionado com Turismo e Cinema, mais concretamente na vertente educacional. Seria, por isso, interessante que no futuro se pudesse continuar a aprofundar esta vertente educacional, nomeadamente através da análise de outros filmes que se enquadrem na mesma vertente que aqui foi proposta.

\section{Referências bibliográficas}

Almeida, D. et al (2009). Cinema e turismo. In José Manuel Simôes \& Carlos Ferreira.

Astérix: O domínio dos deuses. Realização: Louis Clichy e Alexandre Astier. Distribuidora em Portugal: NOS Audiovisuais, 2014, DVD.

Cardoso (Eds). Turismos de nicho. Motivaçōes, produtos, territórios. Centro de Estudos Geográficos, Lisboa.

Aubert, C. (2004). L’individu hypermoderne. Paris: Érès.

Béric D. et al (2013). Film tourism: a contemporary resource for promoting Serbia. Turizam, vol. 17(1), pp. 18-28.

Boniface, B. \& Cooper, C. (2009). Worldwide destinations: The geography of travel and tourism (5. ${ }^{a}$ Ed.). Oxford: Elsevier.

Butler, R. (1980). The concept of a tourism area cycle of evolution: implications for resources. Canadian Geographer, 24(1), pp. 5-12.

Cooper, C.; Fletcher, J.; Fyall, A.; Gilbert, D. \& Wanhill, S. (2005). Tourism, principles and practice. (3. ${ }^{a}$ Ed.). Essex: Pearson Education Limited.

Di Marino, E. (2008). The strategic dimension of destination image. An analysis of the French Riviera image from the Italian tourist's perception [on-line]. http://www.esade.edu/cedit/pdfs/papers/ pdf10.pdf, acedido em 2 de agosto de 2012.

Dumazedier, J. (1962). Vers une civilisation du loisir? Paris: Éditions Seuil.

Duque, A. (2013). O cinema na construção e promoção de territórios turísticos: a imagem do rural no cinema português. Dissertação de Mestrado, UC, Coimbra,https://estudogeral.sib.uc.pt/ bitstream/10316/24547/ [acesso em 03/03/16].

Eusébio, M. (2006). Avaliação do impacte económico do turismo a nível regional. O caso da Regiāo Centro de Portugal. Tese de Doutoramento em Turismo. Departamento de Economia, Gestáo e Engenharia Industrial. Universidade de Aveiro.

Gartrell, R. (1994). Destination marketing for convention and visitors bureaus (2. ${ }^{a}$ Ed.). Kendall: Hunt Publishing Company.

Kotler, P. \& Armstrong, G. (2004). Marketing management: analysis, planning, implementation and

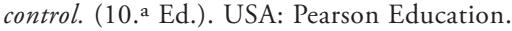

Lickorish, L. \& Jenkins, C. (1997). An introduction to tourism. Oxford: Butterworth-Heinemann.

Lipovestky, G. \& Charles, S. (2004). Os tempos hipermodernos. São Paulo: Barcarolla. 
Mathieson, A. \& Wall, G. (1982). Tourism: economic, physical and social impacts. Harlow: Longman Scientific \& Technical.

Nazareth, L. (2007). The leisure economy: how changing demographics, economics, and generational attitudes will reshape our lives and our industries. Ontario: John Wiley \& Sons.

Orueta, A. E Valdés, C. (2007). Cinema and geography: geographic space, landscape and territory in the film industry. Boletin de la A.G.E., N.o 45, pp. 407-410

Ries, A. \& Trout, J. (1986). Marketing warfare. Journal of Consumer Marketing, 3 (4), pp. 77-82 .

Smith, V. (1989). Introduction. In V - Smith (ed.), Hosts and guests: the anthropology of tourism (2. ${ }^{a}$ Ed.), Philadelphia: University of Pennsylvania Press, pp. 1-17. 